\title{
Chemical Stability of Tricalcium Phosphate-Iron Composite during Spark Plasma Sintering
}

\author{
Mariano Casas-Luna ${ }^{1}$, Miroslava Horynová ${ }^{1}$, Serhii Tkachenko ${ }^{1}$, Lenka Klakurková ${ }^{1}$ (i), \\ Ladislav Celko ${ }^{1}$, Sebastián Diaz-de-la-Torre ${ }^{2}$ and Edgar B. Montufar ${ }^{1, *}$ \\ 1 Central European Institute of Technology (CEITEC), Brno University of Technology, Brno 61200, \\ Czech Republic; mariano.casasluna@ceitec.vutbr.cz (M.C.-L.); horynova@fme.vutbr.cz (M.H.); \\ serhii.Tkachenko@ceitec.vutbr.cz (S.T.); lenka.klakurkova@ceitec.vutbr.cz (L.K.); celko@fme.vutbr.cz (L.C.) \\ 2 Centro de Investigación e Innovación Tecnológica (CIITEC), Instituto Politécnico Nacional, \\ México City 02250, Mexico; sediazt@yahoo.com.mx \\ * Correspondence: eb.montufar@ceitec.vutbr.cz; Tel.: +420-54114-9201
}

Received: 23 July 2018; Accepted: 23 August 2018; Published: 1 September 2018

\begin{abstract}
Tricalcium phosphate $\left(\mathrm{Ca}_{3}\left(\mathrm{PO}_{4}\right)_{2}, \mathrm{TCP}\right)$ is a ceramic widely used as a bone filler material due to its good osteoconductivity. Nevertheless, its poor mechanical properties do not allow its use for load-bearing applications. Therefore, the option of improving its strength and toughness by adding a biocompatible metallic component is a promising alternative to overcome this drawback, leading to the fabrication of improved bone implants. The present work is focused on defining the thermal stability of alpha-TCP $(\alpha-\mathrm{TCP})$ when it is sintered together with iron $(\mathrm{Fe})$ by spark plasma sintering. The results showed the thermal stability of the composite with no degradation or oxidation in the ceramic or metal phase. A clear advantage from the TCP-Fe composites when compared with others, such as hydroxyapatite-titanium, is the complete retention of the TCP due to the less reactivity with iron respect to titanium. Furthermore, the allotropic phase transformation from alpha to beta-TCP polymorph was reduced by sintering at $900{ }^{\circ} \mathrm{C}$. However, the densification of the material was also impaired at this temperature. It is expected that spark plasma sintering will allow the fabrication of TCP-Fe composites free of secondary phases that compromise the mechanical strength of the material.
\end{abstract}

Keywords: metal matrix composite; iron; tricalcium phosphate; sintering; decomposition

\section{Introduction}

In the field of biomaterials, the development of metallic-ceramic composites has attracted the attention of material researchers due to the possibility of combining the mechanical strength and toughness of implantable metals with the osteoconductive properties of calcium phosphate ceramics. Among the different alternatives, titanium and hydroxyapatite are two of the most extensively used materials to treat bone fractures [1,2], so the interactions between them during sintering has been studied in detail $[3,4]$. The results show that the fabrication of titanium-hydroxyapatite composites is technically feasible. However, the disadvantage of this system is that titanium catalyzes the thermal degradation of hydroxyapatite during sintering, generating mixtures of titanium, hydroxyapatite, calcium and titanium oxides and phosphates [4], which leads to detrimental mechanical properties [5]. In the present work, a different system is considered and studied as a potential candidate to overcome this decomposition drawback. Our hypothesis is that tricalcium phosphate-iron (TCP-Fe) powders will be stable during sintering, therefore allowing the fabrication of a new class of biocompatible composite. This premise is based on the fact that tricalcium phosphate is thermodynamically more stable than hydroxyapatite during heating (Figure 1) [6,7]. Besides, as hydroxyapatite, tricalcium 
phosphate is successfully used in the clinic to reconstruct and fill bone defects [2]. Metallic iron, on its side, is less reactive than titanium [8]; consequently, it can increase the chances to retain the tricalcium phosphate phase unreacted. To validate this assumption, alpha-tricalcium phosphate and iron powders were consolidated between 900 and $1100{ }^{\circ} \mathrm{C}$ using the spark plasma sintering technique. The microstructure, crystalline phase composition and mechanical behavior of the resulting composite were studied by scanning electron microscopy (SEM), X-ray diffraction (XRD) and micro-indentation. Spark plasma sintering was used as the forming technique because it allows fast heating rates (up to hundreds of ${ }^{\circ} \mathrm{C} \cdot \mathrm{min}^{-1}$ ) regarding conventional sintering technics and applies uniaxial mechanical load during sintering. These characteristics allow reductions in the processing time and sintering temperature while providing superior mechanical properties due to improved powder densification [9]. A second advantage of the TCP-Fe system is that it can generate a biodegradable composite for temporal biomedical applications. On the one hand, iron is a biodegradable metal with reliable mechanical performance in vivo. In fact, recent works show that iron and its corrosion products are biocompatible [10]. On the other hand, alpha-tricalcium phosphate is slightly more soluble than its beta polymorph, and thus represents a better alternative for the development of a biodegradable composite.

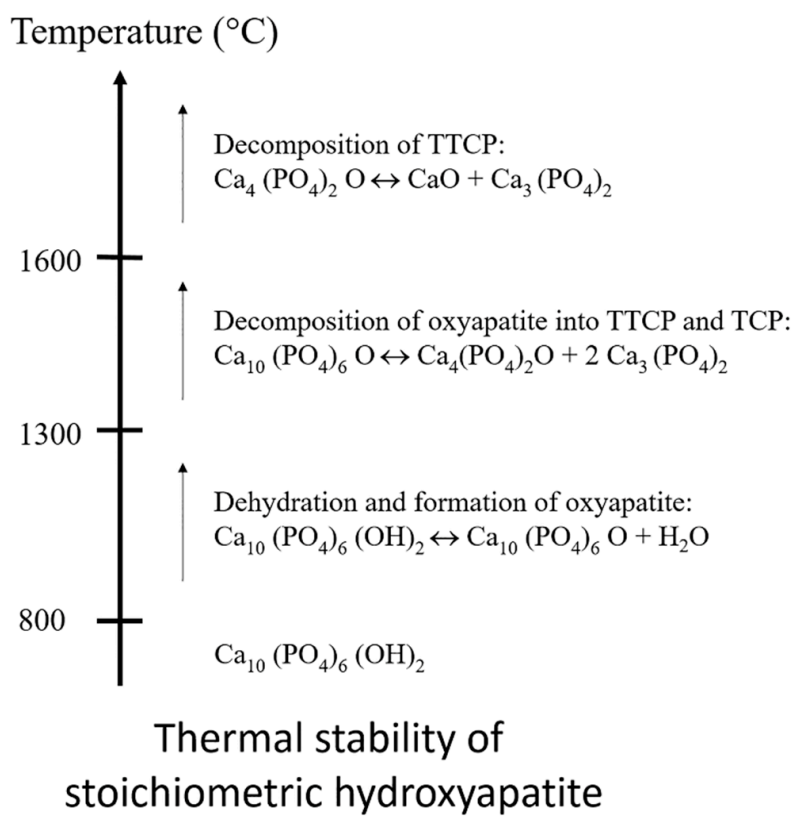

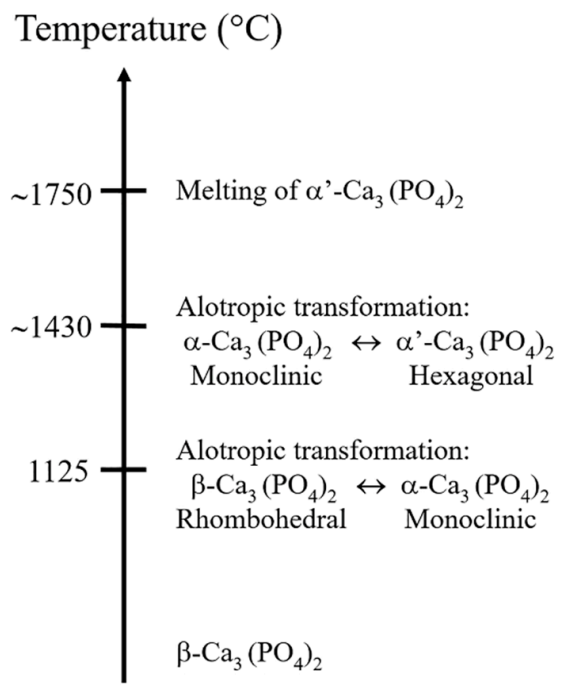

\section{Thermal stability of tricalcium phosphate}

Figure 1. Schematic representation of the thermal stability of stoichiometric hydroxyapatite and crystalline tricalcium phosphate. Data obtained from References [6,7].

\section{Materials and Methods}

\subsection{Preparation of Tricalcium Phosphate-Iron Composite}

Synthesis of alpha-tricalcium phosphate powder was carried out through solid state reaction at $1400{ }^{\circ} \mathrm{C}$ between $\mathrm{CaCO}_{3}$ (Lach-ner, Neratovice, Czech Republic) and $\mathrm{CaHPO}_{4}$ (Merck, Darmstadt, Germany). After the chemical reaction, the product was quenched in air to retain the alpha phase of tricalcium phosphate [11]. Then, tricalcium phosphate was milled using a horizontal high energy ball-mill (Simoloyer CM01, Zoz GmbH, Wenden, Germany) at 1000 rpm for 15 min (until an average particle size below $36 \mu \mathrm{m}$ ) and thoroughly mixed in identical volumetric parts with commercial iron powder containing 3 vol.\% of carbon nanotubes (average particle size of $3.7 \mu \mathrm{m}$. Applied Carbon Nano Technologies, Pohang, Korean). Carbon nanotubes were introduced into the composite to promote the galvanic degradation of iron [12] at the same time to improve the mechanical strength 
of the composite [13]. However, since safety issues related to carbon nanotubes depend on several factors [14], more studies are needed to access their safety or toxicity in this specific exposure condition.

\subsection{Sintering Conditions}

Consolidation of TCP-Fe powder mixture was conducted using a cylindrical graphite die set and a commercial spark plasma sintering system (Dr. Sinter 1050, Sumitomo Coal \& Mining Co. Ltd., now SPS Syntex Inc., Tokyo, Japan) applying a direct current of $600 \mathrm{~A}$ at $3 \mathrm{~V}$ with an on-off cycle of 12 and $2 \mathrm{~ms}$. The sintering temperature was set at 900,1000 and $1100{ }^{\circ} \mathrm{C}$ with a heating rate of $150{ }^{\circ} \mathrm{C} \cdot \mathrm{min}^{-1}$. For monitoring the process temperature, a K-type thermocouple was placed in the center of the wall of the graphite die. No holding time at the sintering temperature was performed; therefore, samples were allowed to cool down after reaching the sintering temperature under vacuum (8 Pa). A constant uniaxial compaction load of $5 \mathrm{kN}(16 \mathrm{MPa})$ was maintained during all the sintering process. Finally, disc-shaped samples of $5 \mathrm{~mm}$ in thickness and $20 \mathrm{~mm}$ in diameter were obtained.

\subsection{Chemical and Microstructural Characterization}

After sintering, for the chemical and microstructural characterization, the obtained discs were ground using $\mathrm{SiC}$ sandpapers measuring 500-grit up to 1200-grit and polished with a diamond paste of $1 \mu \mathrm{m}$ of particle size. XRD analyses (Rigaku SmartLab $3 \mathrm{~kW} \mathrm{CF2,} \mathrm{Tokyo,} \mathrm{Japan)} \mathrm{were} \mathrm{conducted}$ to identify the crystalline phases present in the composite. Scans were performed in Bragg-Brentano geometry between $10^{\circ}$ and $90^{\circ}$, using $\mathrm{Cu} \mathrm{K} \alpha$ radiation and a scan speed of $3^{\circ} \cdot \mathrm{min}^{-1}$. Later, a Rietveld refinement of the XRD patterns was performed using High Score Plus software to determine the percentage of crystalline phases. After the XRD analysis, samples were coated with carbon to observe the microstructure of the polished surfaces by SEM (TESCAN Lyra3, Tescan, Brno, Czech Republic) and prevent charging during observation. Local elemental-composition analyses were performed using an SEM equipped with an energy dispersive X-ray spectrometer (PHILIPS XL30, SEMTech solutions, Billerica, MA, USA). To have an estimation of the degree of consolidation of the tricalcium phosphate phase with respect to the sintering temperature, Vickers hardness measurements were carried out using a microhardness indenter (DuraScan-70, Struers, Puch, Austria) under a load of $100 \mathrm{~g}$ and a dwell time of $15 \mathrm{~s}$. A minimum of ten measurements were performed in each sample and the average value is reported.

\section{Results}

Figure 2a shows the XRD pattern of the TCP-Fe composite sintered at $1100{ }^{\circ} \mathrm{C}$, while Figure $2 \mathrm{~b}$ is a detail of the pattern for a better appreciation of the tricalcium phosphate phase in 2-theta angle between $25^{\circ}$ and $40^{\circ}$. According to the peak indexation, the composite is composed of $\alpha$-iron (ICSD No. 64998), monoclinic tricalcium phosphate ( $\alpha$-phase, ICSD No. 923) and rhombohedral tricalcium phosphate ( $\beta$-phase, ICSD No. 6191). The presence of other phases, such as hydroxyapatite, calcium oxide, iron oxide or carbonates, was not detected.

Rietveld analysis of the diffraction patterns of TCP-Fe composites sintered at 900, 1000 and $1100{ }^{\circ} \mathrm{C}$ (Figure 3) revealed that the average content of $\beta$-tricalcium phosphate in the samples was 10.8 , 38.5 and $44.2 \mathrm{vol} . \%$, respectively. The lowest level of $\beta$-tricalcium phosphate formation was observed at a sintering temperature of $900{ }^{\circ} \mathrm{C}$, which means that the reduction in sintering temperature delays the allotropic phase transformation from metastable $\alpha$-phase into $\beta$-phase. At the same time, the average iron content in the surface of the samples was found to be constant with a value of around $14 \mathrm{vol} . \%$. 
(a)

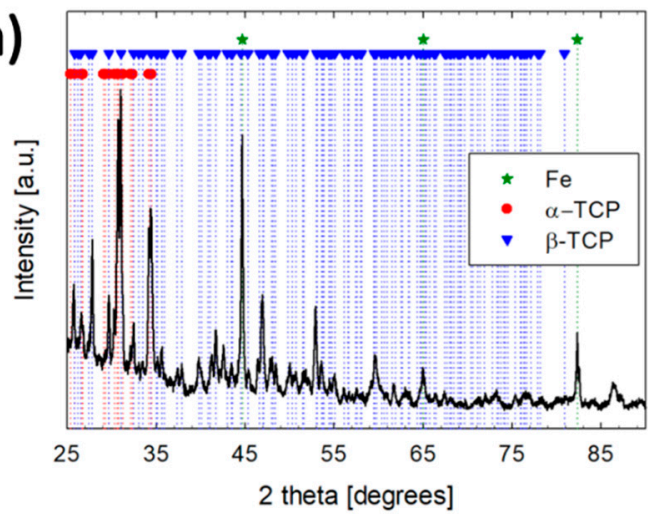

(b)

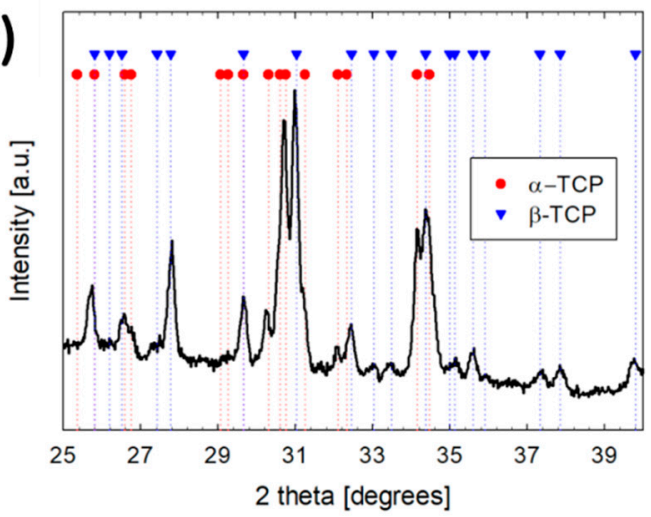

Figure 2. X-ray diffraction (XRD) pattern of (a) the tricalcium phosphate-iron (TCP-Fe) composite surface after spark plasma sintering at $1100{ }^{\circ} \mathrm{C}$ and (b) detail of the pattern showed in (a) in the 2-theta range between 25 and 40 degrees.

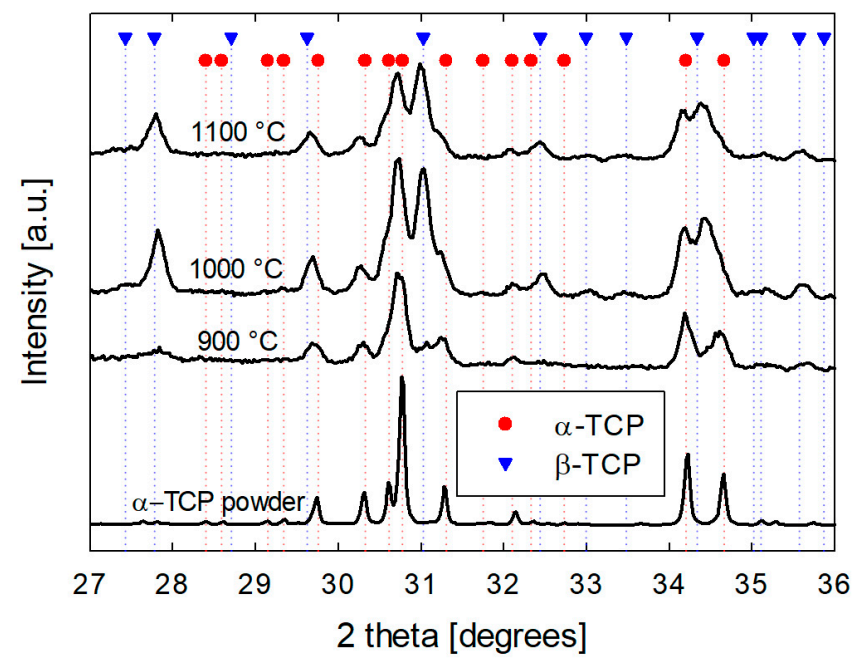

Figure 3. $\mathrm{XRD}$ patterns of the TCP-Fe composite sintered by spark plasma sintering at different temperatures and the starting $\alpha$-TCP powder. The patterns are presented between 27 and 36 (2-theta degrees) to highlight the effect of the sintering temperature on the ratio between $\alpha$ - and $\beta$-tricalcium phosphate polymorphs.

Figure 4 shows backscattered SEM images of the TCP-Fe composite sintered at different temperatures, showing a biphasic microstructure with well-defined boundaries between the phases. As can be corroborated by the elemental analysis spectra presented in Figure 5, the dark phase corresponds to the ceramic phase, composed of calcium, phosphorus and oxygen, presenting a calcium to phosphorus ratio corresponding to tricalcium phosphate i.e., $\mathrm{Ca} / \mathrm{P}=1.5$, while the white phase is iron. The microstructure of the composite processed at $900{ }^{\circ} \mathrm{C}$ featured a weak connection between tricalcium phosphate particles, exhibiting almost free ceramic particles and several pores (Figure 4a), which indicates that the material was not entirely sintered. Nonetheless, since the sintering temperature was increased, better densification was observed with a remaining porosity mainly presented within the ceramic component (Figure $4 \mathrm{~b}, \mathrm{c}$ ). Unexpectedly, less presence of porosity was observed in the material sintered at $1000{ }^{\circ} \mathrm{C}$ in comparison with the higher temperature of $1100{ }^{\circ} \mathrm{C}$. 

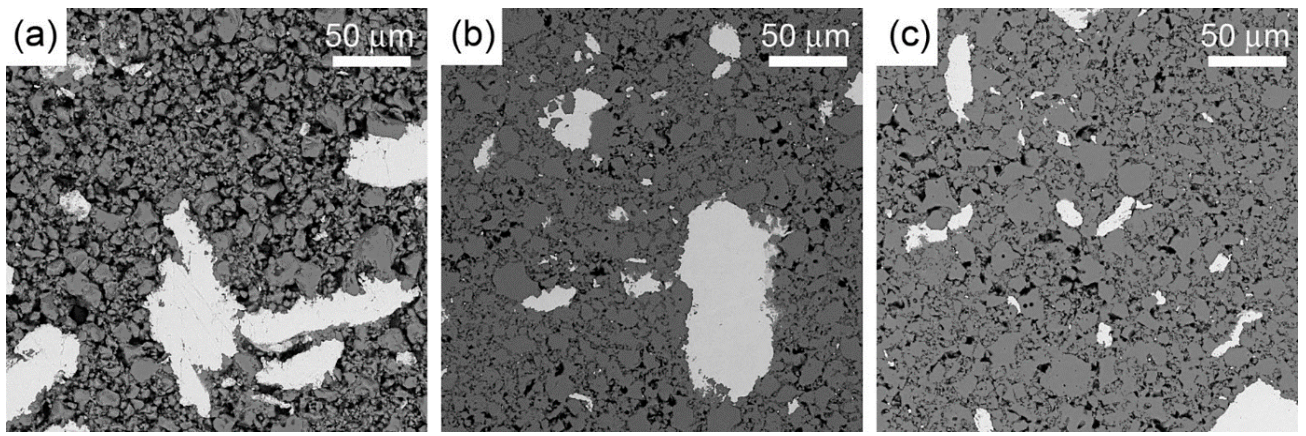

Figure 4. Representative backscattered SEM images of the surface of TCP-Fe composite after spark plasma sintering at (a) $900{ }^{\circ} \mathrm{C}$, (b) $1000{ }^{\circ} \mathrm{C}$ and (c) $1100{ }^{\circ} \mathrm{C}$. The distribution of the two components can be observed, i.e., iron in bright and ceramic in dark grey.
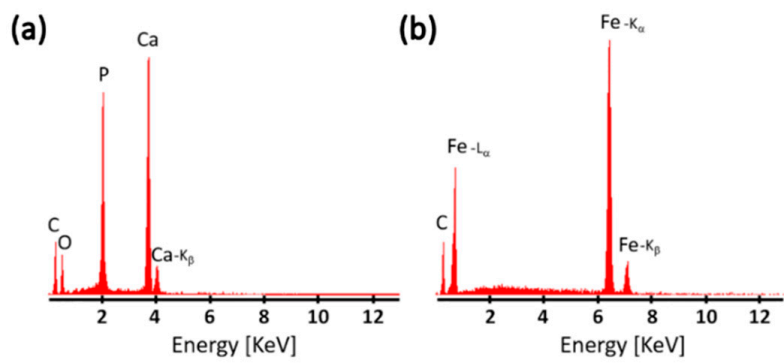

Figure 5. Representative energy-dispersive $X$-ray spectroscopy corresponding to (a) the dark phase (TCP) and (b) the bright phase (Fe) observed in Figure 4.

Figure 6 shows the hardness values measured on the sintered composite, which were specifically carried out only at the tricalcium phosphate phase of the samples. The highest hardness of the ceramic $(1249 \mathrm{MPa})$ was observed for the material sintered at a temperature of $1000{ }^{\circ} \mathrm{C}$, which is followed by the composite sintered at $1100{ }^{\circ} \mathrm{C}$ with a hardness of $1050 \mathrm{MPa}$. These values are in accordance to the degree of porosity that was observed in the micrographies (Figure 4), where higher porosity was present in the samples sintered at $1100{ }^{\circ} \mathrm{C}$. Hardness was not measured on the sample sintered at $900{ }^{\circ} \mathrm{C}$ because it was not thoroughly consolidated, leading to the brittle fracture of the specimen during indentation.

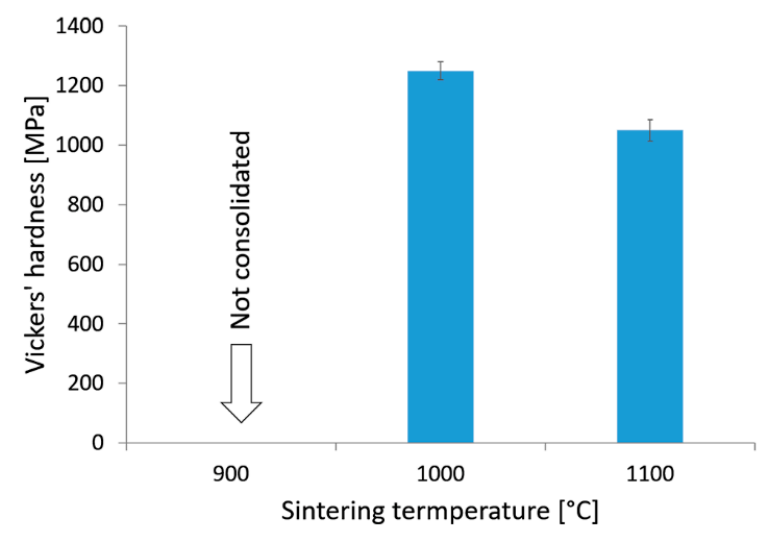

Figure 6. Average of the Vickers' hardness on the ceramic phase of the TCP-Fe composite sintered at temperatures of 1000 and $1100{ }^{\circ} \mathrm{C}$. No consolidation of the composite at the temperature of $900{ }^{\circ} \mathrm{C}$ leads to the brittle fracture of the sample during indentation, giving no results. 


\section{Discussion}

The poor mechanical strength and brittle fracture of calcium phosphate ceramics limit their applications, rendering them unsuitable for bone fracture fixation. In contrast, implantable metals are extensively used to fabricate devices for the internal fixation of bone fractures, such as screws, plates, or even hip prostheses. The combination of calcium phosphate ceramics and metallic reinforcements has been considered as a promising alternative to achieve both bioactivity and mechanical strength in one material. The most commonly explored combination is the composite containing hydroxyapatite matrix toughened with titanium particles [3-5]; however, it has been found that the presence of titanium promotes the partial decomposition of hydroxyapatite during sintering [4]. Therefore, in the present work, we investigated a metal-ceramic composite based on iron and tricalcium phosphate, which could be a good alternative to hydroxyapatite-titanium composites.

The microstructure of the obtained TCP-Fe composite presented a well-defined boundary between the tricalcium phosphate ceramic phase and the metallic iron phase. Moreover, no signs of reaction between the components was detected. As it was corroborated by XRD and the elemental analysis, the existing phases inside the composite corresponded to pure iron particles and pure tricalcium phosphate. In addition, pores were observed within the tricalcium phosphate phase as a result of poor material densification that can be improved in future by varying the sintering conditions, i.e., increasing the compaction load or the dwelling time. Oxidation of iron was avoided because the spark plasma sintering process operates under vacuum. Furthermore, iron did not present reactivity or catalytic degradation effect on the tricalcium phosphate. This could be explained due to the thermal stability of the tricalcium phosphate (Figure 1) and the less reactivity of iron in comparison with other metals like the titanium [15]. In fact, it has been reported that the spark plasma sintering of tricalcium phosphate-titanium powders has led to the partial degradation of the phosphate and the formation of $\mathrm{CaTiO}_{3}$ phases [16]. For the TCP-Fe composite, no formation of $\mathrm{CaO}$ has been found as it is typical in the case of the hydroxyapatite-titanium composites. Therefore, the use of iron represents a step forward to retain unreacted the tricalcium phosphate when these compounds are mixed in a composite. However, the allotropic transformation from $\alpha$ - to $\beta$-polymorph of tricalcium phosphate occurred (Figure 3). There are two main reasons for this transformation. The first is the meta-stability of the alpha phase below $1125^{\circ} \mathrm{C}$ [7] and the second is the diffusive mechanism of phase transformation that is promoted at higher sintering temperatures. In fact, since the beta phase is thermodynamically more stable at 1000 and $1100{ }^{\circ} \mathrm{C}$ and the energy for diffusion is relevant at these two temperatures, around the $50 \%$ of the $\alpha$-tricalcium phosphate was transformed into its beta polymorph. Nonetheless, despite the fact that the beta phase is thermodynamically even more stable than the alpha phase at $900{ }^{\circ} \mathrm{C}$, the slower kinetics of phase transformation governed the process, leading to a higher $\alpha$-tricalcium phosphate retention (around $87 \%$ ). Unfortunately, slow mass diffusion at $900{ }^{\circ} \mathrm{C}$ caused a poor particle consolidation inside the tricalcium phosphate ceramic phase during sintering. It must be pointed out that both alpha and beta tricalcium phosphate polymorphs are biocompatible and osteoconductive ceramics [2]. Therefore, the biocompatibility of the composite should not be affected by the phase transformation of tricalcium phosphate. The interest on retaining the alpha phase is due to its higher bioactivity and solubility than the beta phase [7], allowing the chance of producing a biodegradable and osteoconductive composite in combination with iron, as a biocompatible reinforcement for higher mechanical stability. The sintering process could be performed above the phase transition temperature in order to retain the alpha phase. However, this option presents technical drawbacks, such as a more expensive process due to the higher energy consumption. In the present work, a K-type thermocouple was used to control the sintering temperature in the center of the wall of the graphite die. The use of higher sintering temperature at our laboratory would require the utilization of a pyrometer to measure the temperature on the surface of the graphite die, farther from the sample, with the consequent loss of accuracy. In fact, the control of the real temperature in the sample during the sintering is one of the biggest drawbacks in the spark plasma sintering process [17]. Numerical models have been applied to determine the real temperature distribution inside the sample, but there is not a general solution since 
it depends on several parameters, e.g., geometry and dimensions of the sintering set-up, electrical and thermal properties of the material and frequency of electrical current pulses [17]. Additionally, the increase in the sintering temperature would prolong the cooling time, so the sample would stay at high temperature for longer time and the conditions would be more favorable for phase transformation of the tricalcium phosphate.

Despite of the poor densification with the sintering conditions, the highest hardness of the tricalcium phosphate phase was found to be the half of that reported for bulk tricalcium phosphate ceramics processed by the conventional hot-pressing method [18]. This is an indicator of the superior mechanical properties that can be achieved when using the spark plasma sintering technique in order to decrease the thermal degradation of metal matrix composites that impair the strength and biocompatible properties.

\section{Conclusions}

The spark plasma sintering of iron and tricalcium phosphate powders leads to the consolidation of composite materials free of secondary phases, signs of degradation in its initial components and oxidation. Furthermore, the reduction in the sintering temperature better prevented the phase transformation from alpha to beta phase of tricalcium phosphate in the TCP-Fe composite. Nonetheless, lower temperature reduces the densification of the material, starting the consolidation above $1000{ }^{\circ} \mathrm{C}$. It is expected that the better retention of tricalcium phosphate during sintering with iron will allow the fabrication of osteoconductive and bioactive orthopedic devices with improved mechanical performance.

Author Contributions: Conceptualization-E.B.M.; Data curation-M.C.-L., M.H., S.T. and L.K.; Formal analysis-M.H. and S.T.; Funding acquisition-L.C. and E.B.M. Investigation-M.C.-L.; Methodology-S.D.-T.; Writing original draft-M.C.-L.; Writing review \& editing-L.C., S.D.-T. and E.B.M.

Acknowledgments: This project has received funding from the European Union's Horizon 2020 research and innovation programme under the Marie Skłodowska-Curie and it is co-financed by the South Moravian Region under grant agreement no. 665860. The authors also acknowledge the project CEITEC 2020 (LQ1601) with financial support from the Ministry of Education, Youth and Sports of the Czech Republic under the National Sustainability Program II. Part of the work was carried out with the support of core facilities of research infrastructure CEITEC Nano of CEITEC-BUT. MCL acknowledges the Brno Ph. D. Talent scholarship founded by the Brno City Municipality. SDT acknowledges Consejo Nacional de Ciencia y Tecnología, Mexico, SNI (P.1777000). Thanks to Dr Zdenek Spotz for his support with Rietveld analysis and Guillermo Diéguez-Trejo for his support in spark plasma sintering.

Conflicts of Interest: The authors state that no conflicts of interest exist.

\section{References}

1. Al-Mayouf, A.M.; Al-Swayih, A.A.; Al-Mobarak, N.A.; Al-Jabab, A.S. Corrosion behavior of a new titanium alloy for dental implant applications in fluoride media. Mater. Chem. Phys. 2004, 86, 320-329. [CrossRef]

2. LeGeros, R.Z.; LeGeros, J.P. Calcium phosphate bioceramics: Past, present, future. Key Eng. Mater. 2003, 240, 3-10. [CrossRef]

3. Chu, C.; Xue, X.; Zhu, J.; Yin, Z. Fabrication and characterization of titanium-matrix composite with $20 \mathrm{vol} \%$ hydroxyapatite for use as heavy load-bearing hard tissue replacement. J. Mater. Sci. Mater. Med. 2006, 17, 245-251. [CrossRef] [PubMed]

4. Ye, H.; Liu, X.Y.; Hong, H. Characterization of sintered titanium/hydroxyapatite biocomposite using FTIR spectroscopy. J. Mater. Sci. Mater. Med. 2009, 20, 843-850. [CrossRef] [PubMed]

5. Wang, P.; Chaki, T.K. Sintering behaviour and mechanical properties of hydroxyapatite and dicalcium phosphate. J. Mater. Sci. Mater. Med. 1993, 4, 150-158. [CrossRef]

6. Elliott, J.C. Structure and Chemistry of the Apatites and Other Calcium Orthophosphates; Elsevier Science: Amsterdam, The Netherlands, 1994; Chapter 3.

7. Carrodeguas, R.G.; De Aza, S. $\alpha$-Tricalcium phosphate: Synthesis, properties and biomedical applications. Acta Biomater. 2011, 7, 3536-3546. [CrossRef] [PubMed] 
8. Wulfsberg, G. Oxidation-Reduction Chemistry of the Elements, in: Principles of Descriptive Inorganic Chemistry; University Science Books: Sausalito, CA, USA, 1991; pp. 137-179.

9. Upadhyaya, G.S. Some issues in sintering science and technology. Mater. Chem. Phys. 2001, 67, 1-5. [CrossRef]

10. Francis, A.; Yang, Y.; Virtanen, S.; Boccaccini, A.R. Iron and iron-based alloys for temporary cardiovascular applications. J. Mater. Sci. Mater. Med. 2015, 26, 138-153. [CrossRef] [PubMed]

11. Montufar, E.B.; Maazouz, Y.; Ginebra, M.P. Relevance of the setting reaction to the injectability of tricalcium phosphate pastes. Acta Biomater. 2013, 9, 6188-6198. [CrossRef] [PubMed]

12. Cheng, J.; Zheng, Y.F. In vitro study on newly designed biodegradable Fe- $X$ composites $(X=W, C N T)$ prepared by spark plasma sintering. J. Biomed. Mater. Res. Part B 2013, 101, 485-497. [CrossRef] [PubMed]

13. White, A.A.; Best, S.M.; Kionloch, I.A. Hydroxyapatite-carbon nanotube composites for biomedical applications: A review. Int. J. Appl. Ceram. Technol. 2007, 4, 1-13. [CrossRef]

14. Liu, Y.; Zhao, Y.; Sun, B.; Chen, C. Understanding the toxicity of carbon nanotubes. Acc. Chem. Res. 2013, 46, 702-713. [CrossRef] [PubMed]

15. Sumitomo, N.; Noritake, K.; Hattori, T.; Morikawa, K.; Niwa, S.; Sato, K.; Niinomi, M. Experiment study on fracture fixation with low rigidity titanium alloy. J. Mater. Sci. Mater. Med. 2008, 19, 1581-1586. [CrossRef] [PubMed]

16. Mondal, D.; Nguyen, L.; Oh, I.H.; Lee, B.T. Microstructure and biocompatibility of composite biomaterials fabricated from titanium and tricalcium phosphate by spark plasma sintering. J. Biomed. Mater. Res. A 2013, 101, 1489-1501. [CrossRef] [PubMed]

17. Voisin, T.; Durand, L.; Karnatak, N.; Le Gallet, S.; Thomas, M.; Le Berre, Y.; Castagné, J.F.; Couret, A. Temperature control during spark plasma sintering and application to up-scaling and complex shaping. J. Mater. Proc. Tech. 2013, 213, 269-278. [CrossRef]

18. Himesh, A.; Samar, J.; Kalita, J. Influence of oxide-based sintering additives on densification and mechanical behavior of tricalcium phosphate (TCP). J. Mater. Sci. Mater. Med. 2007, 18, 883-893.

(C) 2018 by the authors. Licensee MDPI, Basel, Switzerland. This article is an open access article distributed under the terms and conditions of the Creative Commons Attribution (CC BY) license (http:/ / creativecommons.org/licenses/by/4.0/). 